\title{
AN IoT-BASED POWER CONTROL AND MONITORING SYSTEM FOR LOW-VOLTAGE DISTRIBUTION NETWORKS
}

\author{
Ngo Minh Khoa ${ }^{1}$, Le Van Dai ${ }^{2,}$, Doan Duc Tung ${ }^{1}$, Nguyen An Toan ${ }^{1}$ \\ ${ }^{1}$ Quynhon University, \\ ${ }^{2}$ Industrial University of Ho Chi Minh City
}

\begin{abstract}
The Internet of Things (IoT) has become an emerging topic of social, technical, and economic significance in recent years. This paper aims to study, design, test, and implement an electric power control and monitoring system in low-voltage distribution networks based on IoT technologies. This system can be remotely controlled and monitored by using IoT devices via a personal computer (PC) or smartphone which is connected to the Internet network. In order to accomplish this goal, a complete tested system including a smart device application, a cloud-based database, an application programming interface, and a hardware setup is proposed in this paper. The electrical variables consisting of the voltage, current, real power, and energy consumption are measured, displayed, and monitored in real-time. Besides, the demand-side management (DSM) technique is also integrated into this tested system to efficiently manage a site's energy consumption with the aim of cutting the cost incurred for power supply. Finally, this electric power control and monitoring system based on IoT technologies allows for the whole monitoring data stored in a cloud-based database that can be analyzed and reported for further purposes.
\end{abstract}

Keywords: Control and monitoring; demand-side management; distribution network; energy consumption; IoT technology

Received: 17/4/2020; Revised: 25/8/2020; Published: 04/9/2020

\section{HÊ THỐNG ĐIỀU KHIỂN VÀ GIÁM SÁT ĐIÊN NĂNG DƯA TRÊN CÔNG NGHỆ IoT ĐỐI VỚI LƯớI ĐIỆN PHÂN PHỐI HẠ ÁP}

\author{
Ngô Minh Khoa ${ }^{1}$, Lê Văn Đại ${ }^{2, *}$, Đoàn Đức Tùng ${ }^{1}$, Nguyễn An Toàn ${ }^{1}$ \\ ${ }^{1}$ Trường Đại hoc Quy Nhon, \\ ${ }^{2}$ Trưòng Đại học Công nghiệp Thành phố Hồ Chí Minh
}

\section{TÓM TẮT}

Trong những năm gần đây, Internet of Things (IoT) đã trở thành một chủ đề về xã hội, kỹ thuật và kinh tế đang được quan tâm đặc biệt. Bài báo này nhằm mục đích nghiên cứu, thiết kế, kiểm tra và triển khai một hệ thống điều khiển và giám sát điện năng dựa trên công nghệ IoT. Hệ thống này có thể được điều khiển và giám sát từ xa bằng cách sử dụng các thiết bị IoT thông qua máy tính cá nhân (PC) hoặc điện thoại thông minh mà nó được kết nối với mạng Internet. Để đạt được mục tiêu này, một hệ thống hoàn chỉnh bao gồm thiết bị thông minh, cơ sở dữ liệu đám mây, tương tác lập trình và hệ phần cứng được đề xuất để nghiên cứu. Các đại lượng điện bao gồm điện áp, dòng điện, công suất tác dụng và điện năng tiêu thụ được đo lường, hiển thị và giám sát trong suốt thời gian thực. Bên cạnh đó, một kỹ thuật quản lý nhu cầu phụ tải (DSM) cũng được tích hợp vào trong hệ thống này để quản lý hiệu quả sự tiêu thụ năng lượng ở phía phụ tải với mục đích nhằm cắt giảm chi phí phát sinh đối với phía nguồn cấp. Cuối cùng, hệ thống này cho phép toàn bộ dữ liệu giám sát tích trữ trong cơ sở dữ liệu đám mây có thể được phân tích và báo cáo cho các mục đích xa hơn.

Từ khóa: Điều khiển và giám sát; quản lý nhu cầu phu tải; mạng phân phối; điện năng tiêu thư; công nghệ IoT

Ngày nhận bài: 17/4/2020; Ngày hoàn thiện: 25/8/2020; Ngày đăng: 04/9/2020

\author{
* Corresponding author. Email: levandai@iuh.edu.vn \\ https://doi.org/10.34238/tnu-jst.3028
}




\section{Introduction}

The Internet of Things (IoT) is an important topic in the technology industry, policy, and engineering circles. This technology has become headline news in both the specialty press and the popular media in recent years. In the electrical engineering sector, IoT technology is becoming more attractive [1]. In this work, the main aim is to study, design, test, and implement an IoT-based system by associating equipment. It can be monitored and controlled from any place in the world only by the authorized personnel at a very low cost.

The IoT application in the electrical engineering sector has been done on previous works [2]-[6]. In reference [2], authors create a prototype system that can control and monitor electrical appliances by using IoT technology. The system can observe energy efficiency base on monitoring and controlling air conditioning appliances and standard overhead lighting units. Authors in [3] have studied the use of IoT in performance monitoring and real-time control of photovoltaic systems. In [4], a scheme of intelligent energy management based on IoT application is proposed for monitoring a smart home. The low-cost IoT energy monitoring system was proposed in [5]. This system is designed and implemented by using many applications such as electricity billing system, energy management in smart grid and home automation. This designed and implemented system is based on a low-cost voltage sensor, current sensors, and an SD3004 electric energy measurement chip and an ESP8266 WeMos D1 microcontroller for retrieving data from sensor nodes and sending data to the server via the internet. In [6], authors describe a novel low-cost IoT sensor for measuring and analyzing power quality at the input of any individual alternating current appliance, providing an early detection and analysis system which controls those critical variables inside the facility and leads to anticipate faults with early-stage alerts based on on-time data streams treatment.

Related to using IoT devices to control and monitor the electric power, the works in [7][11] present many studies about application IoT devices such as Arduino microcontrollers, voltage, current sensors, smart meters, smartphones, etc. These devices are used to design and implement low-cost systems for measuring in smart meters [8], [9] and for monitoring and controlling smart home energy management systems [10], [11]. Based on the above analyses and the motivation of future reality. this paper study, design, test, and implement an electric power control and monitoring system based on IoT technologies in the laboratory-scale system to better help students understanding the application of IoT technologies for the control and monitoring electric power in low-voltage distribution networks.

The rest of this paper is organized as follows. the hardware and software of the control and monitoring electric power in low-voltage distribution networks are developed in Section 2. The experimental results and discussion are discussed in Section 3. Finally, Conclusion is presented in Section 4.

\section{Proposed system}

\subsection{Hardware design}

In this paper, we design the electric power control and monitoring system for singlephase low-voltage distribution networks. The block diagram of the proposed system is presented in Figure 1. In which, the circuits no. 1,2 and 3 represent the power supply, load no. 1, and load no. 2, respectively. The voltage signal of the circuit 1 is acquired by a voltage sensor (ZMPT101B) which is denoted by the voltage transformer (VT). The current signals of three circuits are also acquired by three current sensors (ACS712) which are denoted by the current transformer CT1, CT2, and CT3 respectively. Also, a relay is 
installed for each circuit with the purpose to control the circuit. These relays are controlled by an Arduino WeMos microcontroller board which is used to program according to proposed algorithms for calculating electrical quantities from the voltage and current sensors. The electrical variables including the root mean square (RMS) voltage, RMS current, real power and energy consumption of three circuits are measured and displayed on the local liquid crystal display (LCD). Besides, they are also transmitted to a personal computer or smartphone via a Wi-Fi Internet network. This means that the system can be remotely monitored and controlled in real-time.

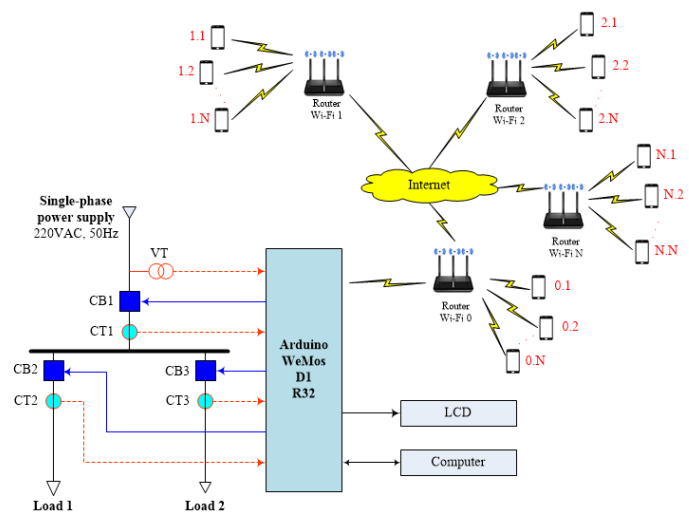

Figure 1. The proposed test system

\subsection{Software design}

The measurement background of electrical quantities which is calculated in the proposed system is carried on according to the standard IEEE Std. $1459^{\mathrm{TM}-2010}$ [12]. It is supposed that the voltage waveform of the ZMPT101B sensor output is sinusoidal with its amplitude $\left(U_{m}\right)$ and the initial phase angle equals zero. The voltage waveform is sampled by an analog-digital converter (ADC) in Arduino WeMos with a sampling time $(\Delta t)$ as follows [7], [12].

$$
u(k)=U_{m} \sin (k \omega \Delta t)
$$

where $U_{m}$ is the voltage amplitude, $\omega=2 \pi f$, $f$ is the frequency $(\mathrm{Hz}), \Delta t$ is the sampling time (s); $k$ is the $k^{\text {th }}$ sample.
The RMS is the square average of samples in a sampling duration. Therefore, the RMS voltage $\left(U_{r m s}\right)$ is determined as follows:

$$
U_{r m s}=\sqrt{\frac{1}{N} \sum_{k=1}^{N}(u(k))^{2}}
$$

where $u(k)$ is the $k^{\text {th }}$ voltage sample; $N$ is the total of voltage samples.

It is supposed that the output current waveform of ACS712 sensor is also sinusoidal with its amplitude $\left(I_{m}\right)$ and initial phase angle equal $\varphi$. The current waveform is also sampled by an ADC in Arduino WeMos with a sampling time $(\Delta t)$ as follows [7], [12].

$$
i(k)=I_{m} \sin (k \omega \Delta t-\varphi)
$$

where $I_{m}$ is the current amplitude.

Therefore, the RMS current $\left(I_{r m s}\right)$ of the current signal will be determined as follows:

$$
I_{r m s}=\sqrt{\frac{1}{N} \sum_{k=1}^{N}(i(k))^{2}}
$$

where $i(k)$ is the $k^{\text {th }}$ current sample; $N$ is the total of current samples.

If an instantaneous power is real power at any instant of time, then

$$
\begin{aligned}
p(k) & =u(k) i(k) \\
& =\left[U_{m} \sin (k \omega \Delta t)\right]\left[I_{m} \sin (k \omega \Delta t-\varphi)\right] \\
& =U_{m} I_{m}[\sin (k \omega \Delta t) \sin (k \omega \Delta t-\varphi)]
\end{aligned}
$$

where $p(k)$ is the $k^{\text {th }}$ instantaneous real power sample, $u(k)$ is the $k^{\text {th }}$ voltage sample, $i(k)$ is the $k^{\text {th }}$ current sample.

Therefore, the real power is an average of instantaneous real power in a sampling duration and it is determined as follows:

$$
P=\frac{1}{N} \sum_{k=1}^{N} p(k)=\frac{1}{N} \sum_{k=1}^{N} u(k) i(k)
$$

The energy consumption is

$$
A=P \times t
$$

Based on the measurement background mentioned above, we build an algorithm for measuring electrical quantities as shown in 
Figure 2. The algorithm is programmed on Arduino IDE software and then uploaded to the Arduino WeMos microcontroller.

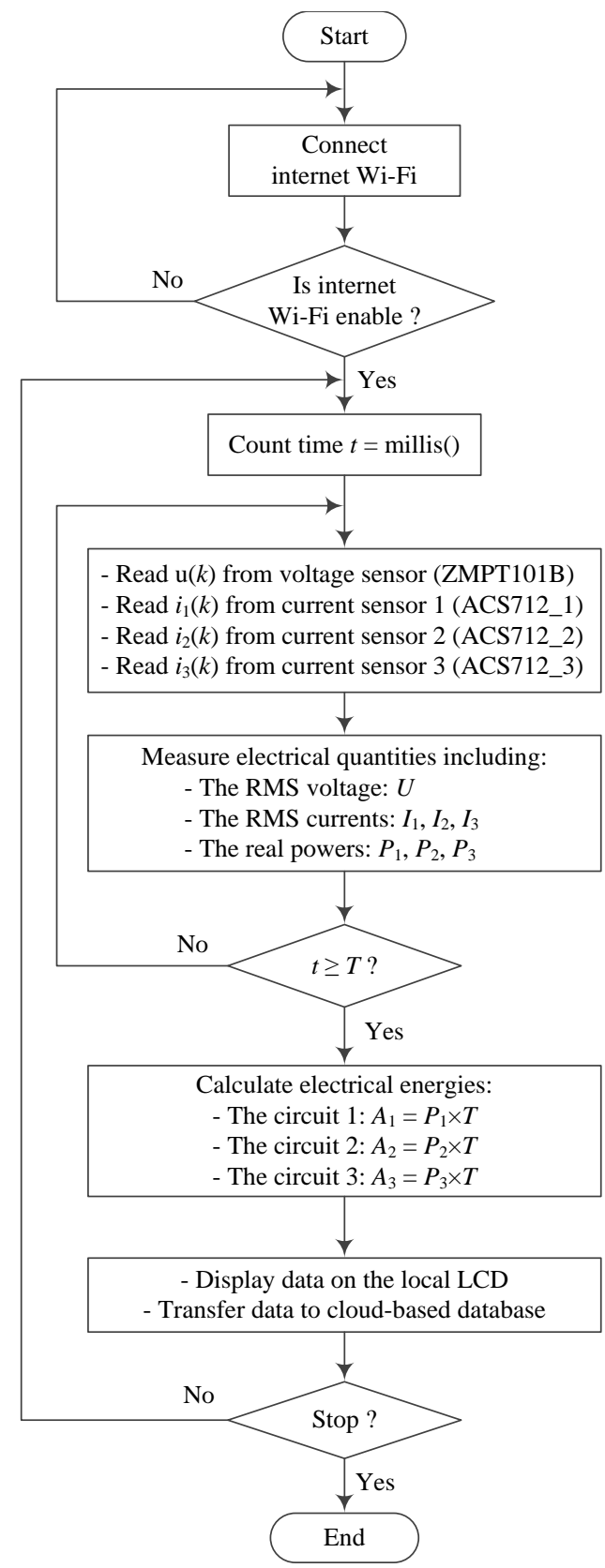

Figure 2. The proposed algorithm for measuring electrical quantities

Demand-side management (DSM) is the planning, implementation, and monitoring of grid interaction designed to produce changes in the neighborhood's load shape by changing the energy consumption magnitude and timerelated patterns [13], [14]. The functionalities of DSM revolve around the six strategies shown in Figure 3.

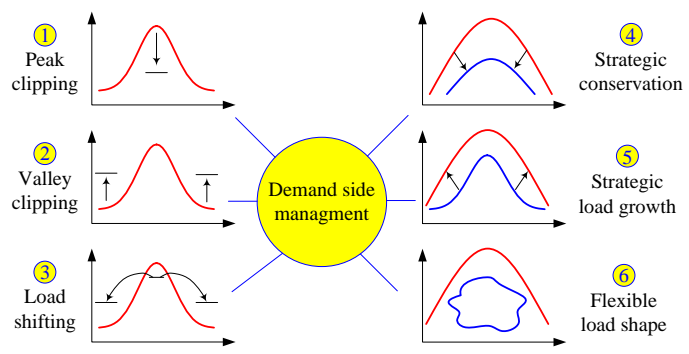

Figure 3. Demand-side management strategies

In this paper, we apply two DSM strategies including peak clipping and valley filling methods in order to implement into the proposed system. The total real power of circuit 1 is compared to the minimum real power $\left(P_{\min }\right)$ and the maximum real power $\left(P_{\max }\right)$ to give a control decision of peak clipping or valley filling accurately. The DSM algorithm is as follows:

If $P_{1}>P_{\max }$ then the load 2 will be turned off after 3 seconds and the total real power of the circuit 1 will equal to the real power of the load 1.

If $P_{1}<P_{\min }$ then the load 2 will be turned on after 3 seconds and the total real power of the circuit 1 will equal to the real power of loads 1 and 2.

In order to remotely monitor and control using a PC or smartphone via Wi-Fi Internet, we apply the Blynk App to design a control and monitoring software. This software is used to monitor electrical quantities including the RMS voltage, RMS current, real power, and energy consumption in the system. Besides, the software can be used to control the relays and to accomplish the DSM function. Each object on the Blynk App is assigned by a virtual variable to update continuous data transmission between Arduino WeMos microcontroller and cloudbased database in real-time. The proposed control and monitoring algorithm on the Blynk App is shown in Figure 4. 


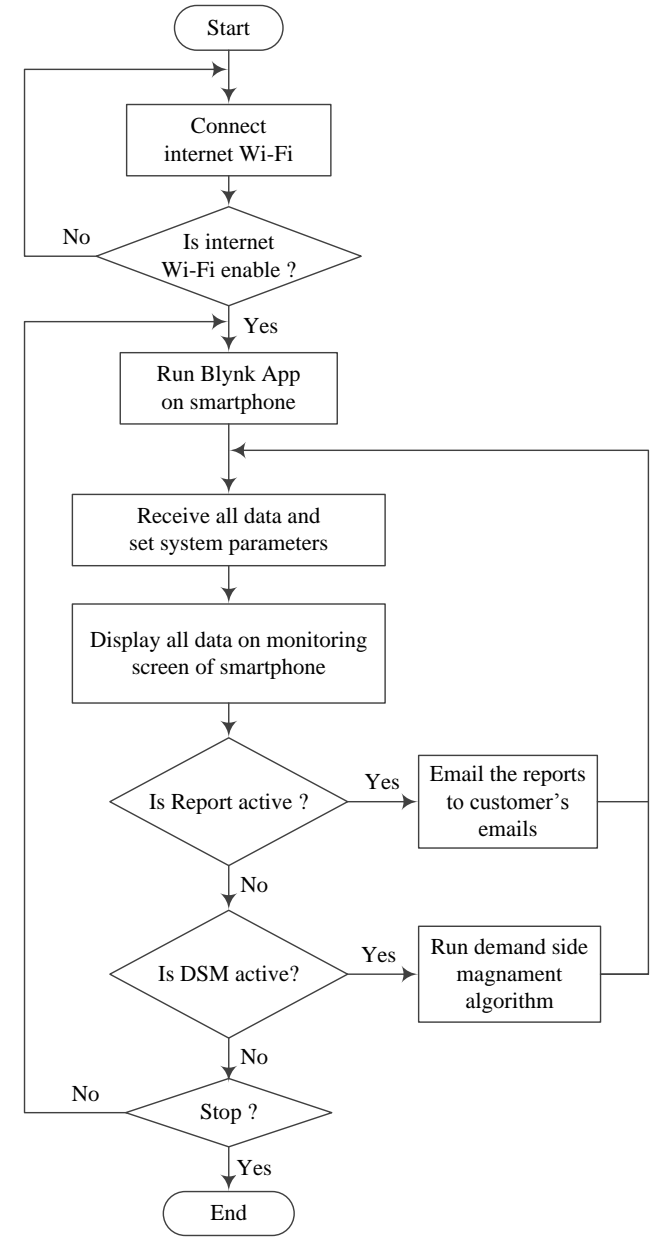

Figure 4. The algorithm on the Blynk App

The user interface on the smartphone is shown in Figure 5. From this interface, we can carry on functions including (i) open/close the relays of circuits; (ii) on/off DSM function; (iii) vary the setting of $P_{\text {min }}$ and $P_{\max }$; and (iv) display RMS voltage, RMS current, real power, and energy consumption. Besides, we can also execute reporting functions to send time information and the measurements to the desired email. Therefore, customers can easily manage their energy consumption. The customers can select one of four reporting modes as follows:

(i) Monthly report, if this method is selected, the program will email to the customer the energy consumption on the last date of the specified month or every month. (ii) Weekly report, if this method is selected, the program will email to the customer the energy consumption on the weekend of the specified week or every week.

(iii) Daily report, if this method is selected, the program will email to the customer the energy consumption of the specified date or every day.

(iv) One time report, if this method is selected, the program will email to the customer to inform the energy consumption when the function is active.

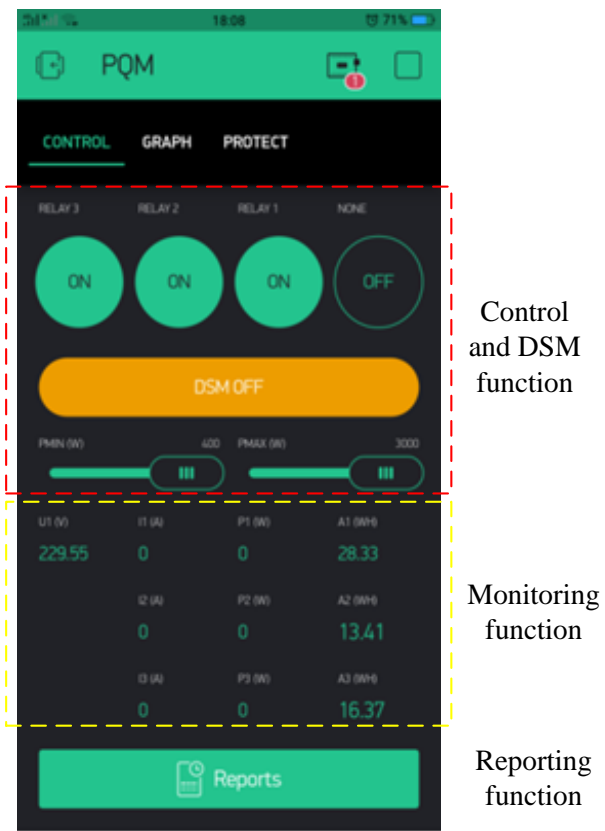

Figure 5. The user interface on the smartphone

\section{Experimental results and discussion}

The proposed system is developed as shown in Figure 6. The LCD in this system is used to display measurement parameters. To make experiments, electrical appliances are used to represent for the loads in the system. Therefore, it is supposed that the load 1 is $4 \times 60 \mathrm{~W}$ bulbs and load no. 2 is the $750 \mathrm{~W}$ hairdryer. Moreover, to transmit all measurement data to a cloud-based database, the system must first be established to connect a Wi-Fi internet network at the installation location as shown in the algorithm of Figure 4. After installing the experimental 
system, the Blynk App which is designed on smartphones is run to control and monitor remotely the system.

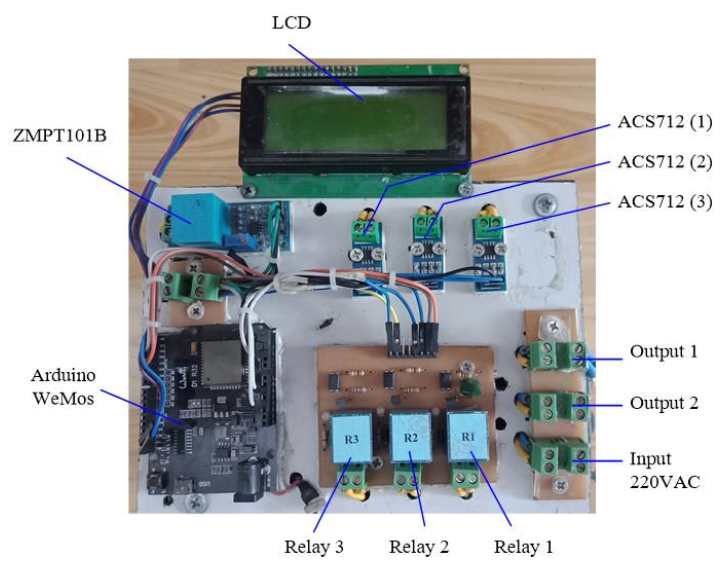

Figure 6. The experimental setup

On the smartphone, after the Blynk App is linked to the system all measurement parameters as mentioned in Subsection 2.2 are displayed under a numerical type as Figure 7(a) or a graphical type as Figure 7(b). This means that the system can help us easily monitor all measurements in real-time. In addition, we can make a manual action to control the circuits in the system by clicking on the push button of the relay. The reporting function is also done in Figure 7(a) by selecting the reports button on the interface. Then we select a reporting mode to export the desired monitoring results.

In order to show the effectiveness of the system, two experimental monitoring results are presented in this paper. Firstly, a 15minute monitoring result that is exported from the system is shown in Figure 8. The voltage, current, real power and energy consumption measurements are shown by an order from top to bottom in Figure 8. From the results, we can see that the measurements are updated every minute. Secondly, a 24-hour monitoring result which is exported from the system is shown in Figure 9. The two results show that the grid voltage oscillates around the nominal voltage $220 \mathrm{~V}$. The current, real power varies their values because the loads are turned on/off while the experiments are carried on. Finally, the energy consumption increases time-by-time.

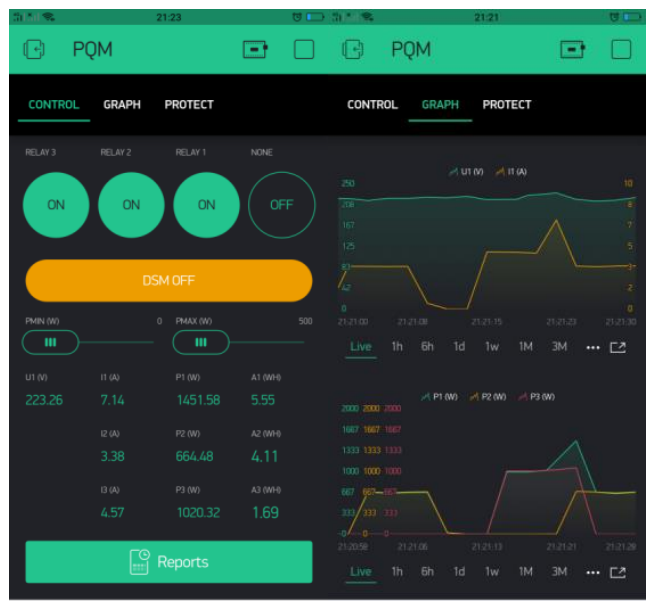

(a) Numerical type

(b) Graphical type

Figure 7. Experimental results on the smartphone
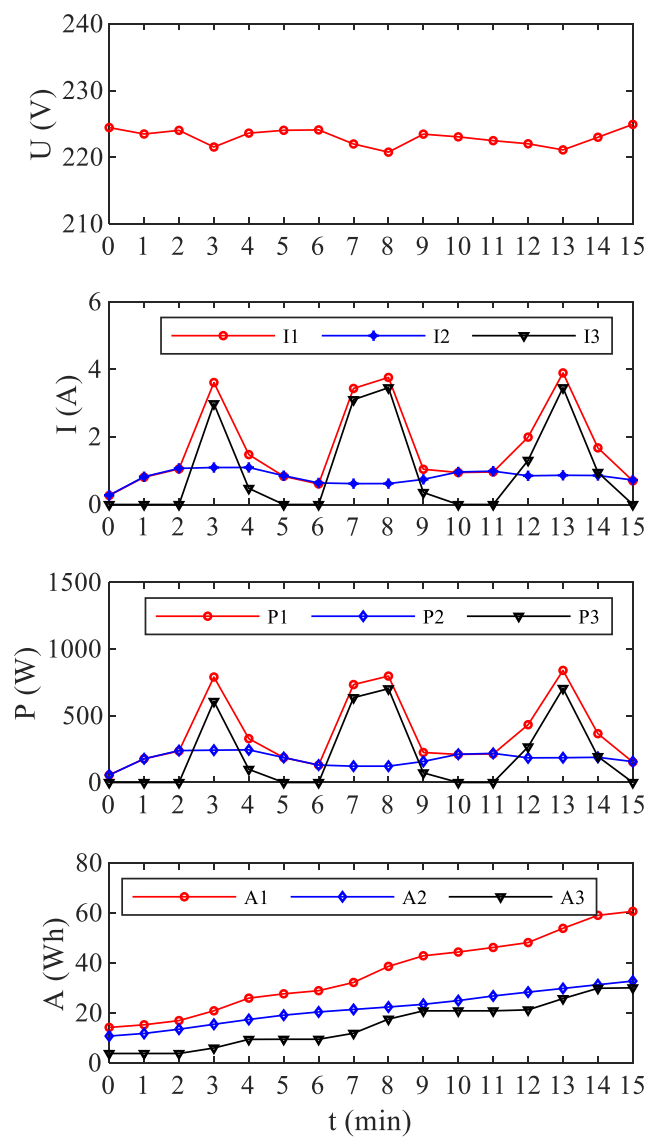

Figure 8. The experimental result in monitoring 15-minute 

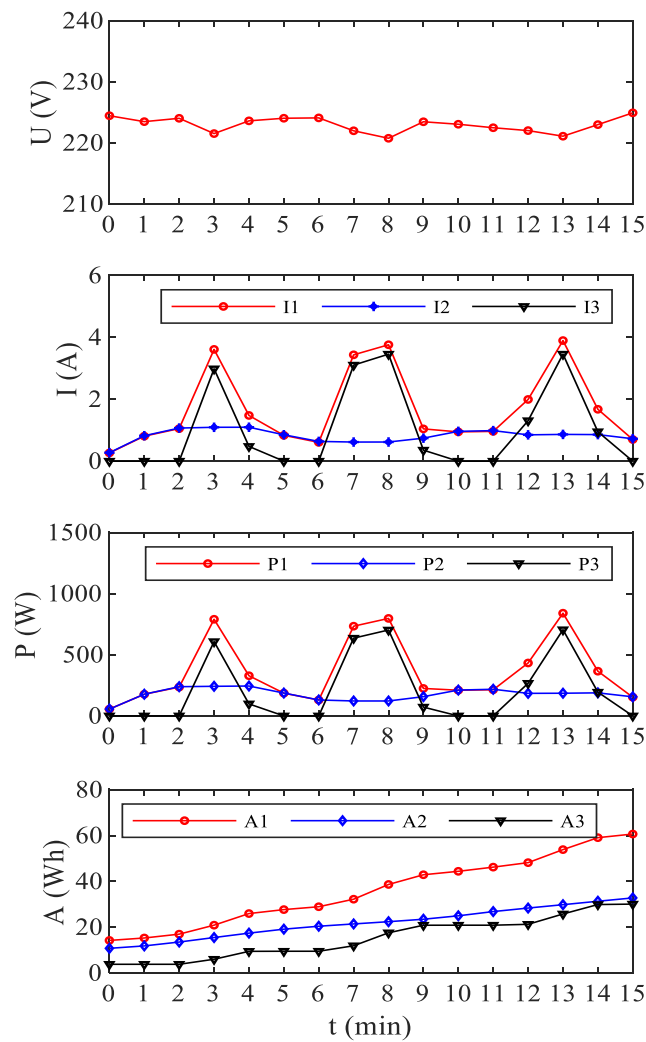

Figure 8. The experimental result in monitoring 15-minute
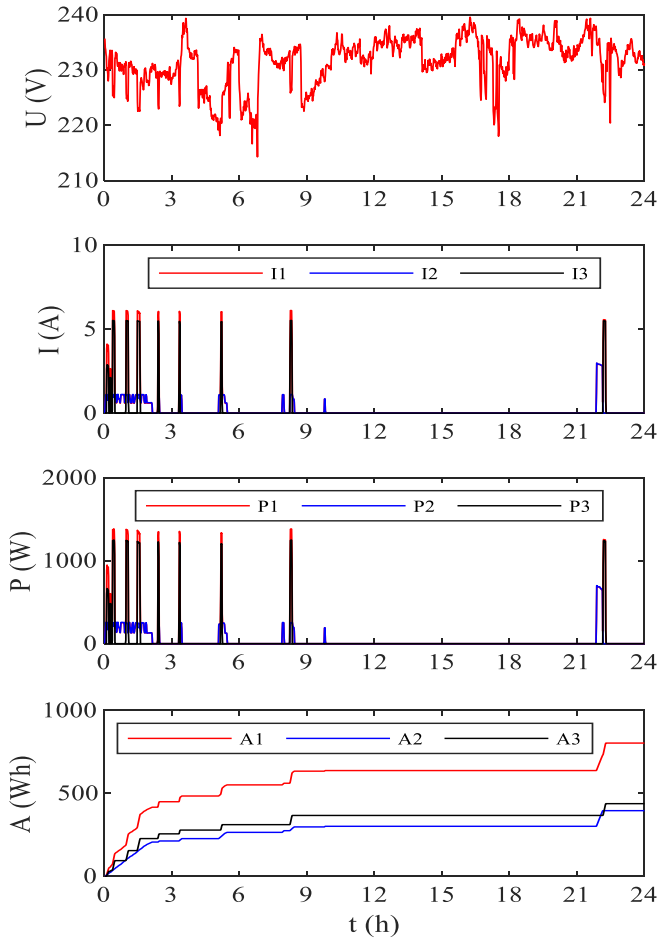

Figure 9. The experimental result in monitoring 24-hour
In this work, to evaluate the DSM algorithm which is presented in Subsection 2.2, the DSM function is activated via the button on Figure 7(a) and then the minimum and maximum power settings are set to $150 \mathrm{~W}$ and $750 \mathrm{~W}$, respectively. It is supposed that load 1 of the system is varied by turning on/off the bulbs. This experimental result is displayed in Figure 10, which shows a captured snapshot of the monitoring result when the DSM function is activated in the period of the experiment. Two circlelocations on the snapshot are the instants at which the DSM function is done to valley and peak clipping, respectively.

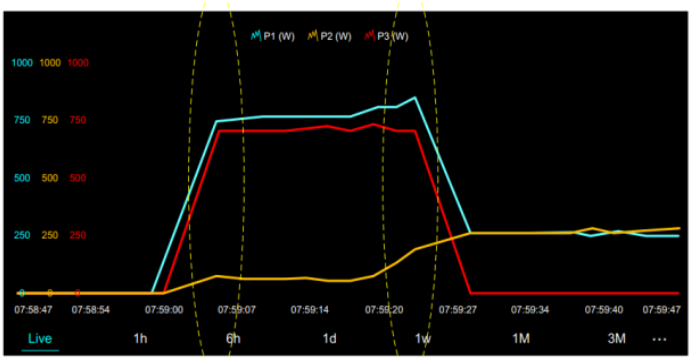

$$
\text { (Load } 2 \text { is turned on) } \quad \text { (Load } 2 \text { is turned off) }
$$

Figure 10. A snapshot of DSM technique

\section{Conclusion}

In this paper, a 220VAC single-phase low-cost electric power control and monitoring system based on IoT technology is designed and tested in a laboratory at the authors' University. The Electrical variables consisting of the root mean square (RMS) voltage, RMS current, real power and energy consumption can remotely be measured, controlled and monitored using a $\mathrm{PC}$ or smartphone which is connected to the Internet. The demand-side management technique is also implemented into the system for efficiently managing a site's energy consumption. The experimental results shown that the system operated accurately and efficiently. From these experimental results, it can be seen that the proposed system can control and monitor electric power for lowvoltage distribution networks. Finally, the system can also be developed with more new features in the future. 


\section{Acknowledgments}

This work was supported by the project B2020-DQN-02 sponsored by the Ministry of Education and Training, Vietnam.

\section{REFERENCES}

[1]. G. Bedi, R. Singh, and K. C. Wang, "Review of Internet of Things (IoT) in Electric Power and Energy Systems," IEEE Internet of Things Journal, vol. 5, no. 2, pp. 847-870, 2018.

[2]. W. T. Hartman, A. Hansen, E. Vasquez, S. ElTawab, and K. Altaii, "Energy monitoring and control using Internet of Things (IoT) system," in Proc. 2018 Systems and Information Engineering Design Symposium, 2018, pp. 13-18.

[3]. N. M. Kumar, K. Atluri, and S. Palaparthi, "Internet of Things (IoT) in Photovoltaic Systems," in Proc. 2018 National Power Engineering Conf., Madurai, India, 2018, pp. 1-4.

[4]. T. Y. Yang, C. S. Yang, and T. W. Sung, “An Intelligent Energy Management Scheme with Monitoring and Scheduling Approach for IoT Applications in Smart Home," in Proc. 2015 Third Int. Conf. Robot, Vision and Signal Processing, Kaohsiung, Taiwan, 2015, pp. 216-219.

[5]. H. Luan, and J. Leng, "Design of energy monitoring system based on IoT," in Proc. 2016 Chinese Control and Decision Conference, Bangkok, Thailand, 2016, pp. 6785-6788.

[6]. A. R. Manuel, G. C. Aurora, M. G. Ricardo, M. M. Antonio, and C. C. Eduardo, "Novel Internet of Things Platform for In-Building Power Quality Submetering," Applied Sciences, vol. 8, p. 1320, 2018.

[7]. P. Srividyadevi, D. V. Pusphalatha, and P. M. Sharma, "Measurement of Power and Energy Using Arduino," Research Journal of
Engineering Sciences, vol. 2, no. 10, pp. 10$15,2013$.

[8]. G. Aurilio, D. Gallo, C. Landi, M. Luiso, V. Cigolotti, and G. Graditi, "Low cost combined voltage and current transducer for Smart Meters," in Proc. 2014 IEEE Int. Instrumentation and Measurement Technology Conf., Montevideo, Uruguay, 2014, pp. 1459-1464.

[9]. D. D. Santis, D. A. Giampetruzzi, G. Abbatantuono, M. La, S. Fellow, and P. Bari, "Smart Metering for Low Voltage Electrical Distribution System using Arduino Due," in Proc. 2016 IEEE Workshop on Environmental, Energy, and Structural Monitoring Systems, Trento, Italy, 2016, pp. 1-6.

[10]. M. J. Mnati, A. V. Bossche, and R. F. Chisab, "Smart Voltage and Current Monitoring System for Three Phase Inverters Using an Android Smartphone Application," Sensors, vol. 17, p. 872, 2017.

[11]. D. M. Han, and J. H. Lim, "Design and implementation of smart home energy management systems based on ZigBee," IEEE Trans. Consumer Electronics, vol. 56, no. 3, pp. 1417-1425, 2010.

[12]. IEEE Std $1459^{\mathrm{TM}}-2010$, IEEE Standard Definitions for the Measurement of Electric Power Quantities Under Sinusiodal, Nonsinusoidal, Balanced, or Unbalanced Conditions, IEEE Power \& Energy Society, 19 March 2010.

[13]. M. Jamil, and S. Mittal, "Hourly load shifting approach for demand side management in smart grid using grasshopper optimisation algorithm," IET Generation, Transmission \& Distribution, vol. 14, no. 5, pp. 808-815, 2020.

[14]. M. Latifi, A. Khalili, A. Rastegarnia, W.M. Bazzi, and S. Sanei, "Demand-side management for smart grid via diffusion adaptation," IET Smart Grid, vol. 3, no. 1, pp. 69-82, 2020. 